\title{
EL CORRECTO FUNCIONAMIENTO DE LA ADMINISTRACIÓN PÚBLICA: FUNDAMENTO DE INCRIMINACIÓN DE LOS DELITOS VINCULADOS A LA CORRUPCIÓN PÚBLICA*
}

\section{Rafael H. Chanjan Documet ${ }^{* *}$}

\begin{abstract}
Resumen: El presente estudio pretende efectuar un análisis político-criminal y dogmático penal de la intervención del Derecho penal en el ámbito de los delitos contra la administración pública, de tal manera que se examine la legitimidad del Derecho penal en la prevención de la corrupción pública. En ese sentido, se demostrará que este tipo de delitos no busca sancionar las meras desobediencias a la autoridad o infracciones de deberes y principios éticos funcionariales, sino fundamentalmente asegurar que la función pública misma cumpla las finalidades sociales de carácter prestacional constitucionalmente
\end{abstract}

* El presente artículo se elaboró sobre la base de la tesis de licenciatura defendida por el autor en la Pontifica Universidad Católica del Perú bajo la dirección del Dr. Yvan Montoya Vivanco y cuya calificación obtuvo la máxima mención de sobresaliente.

** Doctorando en Derecho por la Universidad de Murcia (España). Máster en Derecho Penal y Política Criminal por la Universidad de Málaga (España). Máster en Derecho Penal Económico Internacional por la Universidad de Granada (España). Profesor de la Pontificia Universidad Católica del Perú (PUCP). Miembro Grupo de Investigación en Derecho Penal y Corrupción (DEPEC) de la PUCP. Lima, Perú. Correo-e: rchanjan@pucp.pe.Fecha de recepción: 5 de diciembre de 2016. Fecha de modificación: 26 de mayo de 2017. Fecha de aceptación: 31 de agosto de 2017. Para citar el artículo: RAFAEL H. Chanjan Documet. "El correcto funcionamiento de la administración pública: fundamento de incriminación de los delitos vinculados a la corrupción pública”, en Revista Derecho Penal y Criminología, Vol. 38, n. ${ }^{\circ}$ 104, enero-junio de 2017, Bogotá, Universidad Externado de Colombia, pp. 121-150. DOI: https://doi.org/10.18601/ 01210483.v38n104.04 
asignadas. La administración pública, entendida como función pública, merece la tutela penal en la medida en que es el instrumento a través del cual el Estado hace llegar de manera igualitaria los servicios públicos, como educación, salud, seguridad, etc., a los ciudadanos, posibilitando el disfrute efectivo de sus derechos fundamentales. Sobre esta base, se mostrará cómo es que el correcto funcionamiento de la administración pública es el bien jurídico genérico, de naturaleza colectiva, o ratio legis en los delitos vinculados a la corrupción en el ámbito público.

Palabras Clave: Bien jurídico general, Bienes jurídicos colectivos, Función pública, Correcto funcionamiento de la administración pública, Corrupción pública, Derecho penal, Política criminal.

\title{
THE CORRECT FUNCTIONING OF PUBLIC ADMINISTRATION: REASON OF PUNISHMENT OF CRIMES RELATED TO PUBLIC CORRUPTION
}

\begin{abstract}
This paper aims to make a criminal policy and criminal theory analysis of the intervention of Criminal Law in the field of offences against public administration, so that the legitimacy of criminal law in preventing public corruption is under consideration. In that sense, this study will show how this kind of offences does not seek to punish mere disobediences to the authority or breaches of duties and ethical principles of the public workers, but essentially ensure that the public service itself accomplishes the social aims constitutionally foreseen. Public administration, understood as a public service, deserves criminal protection insofar as it is the instrument through which the State offers equally public services such as education, health, safety, etc., to citizens, enabling the effective enjoyment of their fundamental rights. On this basis, this paper will show how the proper functioning of public administration is the generic legally protected object, of a collective nature, or ratio legis in offences linked to corruption in the public domain.
\end{abstract}

Keywords: Legally protected object, Public function, Proper functioning of public administration, Public corruption, Criminal Law, Criminal Policy.

\section{INTRODUCCIÓN}

Los actos de corrupción que se producen en el seno de la función que desempeñan los servidores y funcionarios de los Estados, ciertamente, producen entre la población indignación, más aún cuando se trata de corrupción al más alto nivel de la función pública. Frente a esta realidad, el Derecho penal suele ser la herramienta que más se aclama a fin de sancionar y expulsar de la función pública a aquellos "malos" funcionarios que traicionan la confianza depositada en ellos. No obstante, desde la 
academia merece la pena detenerse a analizar y determinar qué papel debe cumplir -más allá del rol que cumple en la realidad- el Derecho penal en este ámbito de las relaciones sociales.

Si se entiende al Estado como un ente abstracto cuya razón de ser última es precisamente la maximización y efectivización de la dignidad de la persona humana y sus derechos, hay que reconocer que la administración pública o, en otras palabras, la función pública cumple un rol fundamental en dicha labor del Estado, en la medida en que es el medio o instrumento a través del cual los ciudadanos van a recibir las bondades del Estado; es decir, conforme ya lo ha reconocido el Tribunal Constitucional peruano, la administración pública es el medio mediante el cual el Estado hace llegar de manera eficiente e igualitaria los servicios públicos a la población a fin de satisfacer sus necesidades y derechos fundamentales.

Como veremos a continuación, el Derecho penal, en tanto mecanismo estatal de control social, va a legitimarse cuando tenga como finalidad prevenir estos actos de corrupción pública -respetando garantías fundamentales- que ponen en grave riesgo el correcto desempeño de la función pública y, por ende, en última instancia, afecten el disfrute de los derechos fundamentales de las personas. El Derecho penal merece intervenir en este ámbito, dado que los actos de corrupción pública constituyen actividades que reducen las posibilidades de que los ciudadanos reciban en condiciones de igualdad los servicios públicos por parte del Estado.

Para tal efecto, en principio se llevará a cabo una aproximación a la naturaleza, características y finalidades de la administración pública, lo cual obliga previamente a tratar de manera sucinta el paradigma del Estado Social y Constitucional de Derecho. Asimismo, se explicará el rol del Derecho penal en el ordenamiento jurídico y la sociedad, sus fines preventivos y garantistas, a efectos de analizar los aspectos político-criminales que fundamentan la sanción penal de conductas funcionariales en el marco de la administración pública. Por último, se realizará un análisis de lo que se entiende por bien jurídico-penal, y en específico abordaremos el tema de los bienes jurídicos colectivos para determinar el objeto de tutela general en los delitos contra la administración pública.

\section{ESTADO SOCIAL Y DEMOCRÁTICO DE DERECHO Y ROL DE LA ADMINISTRACIÓN PÚBLICA}

El abordaje del fundamento o razones político-criminales que inspiran la sanción penal de conductas que atentan contra la administración pública exige, en primer lugar, entender el papel de la administración pública en el Estado moderno, pues es dentro de esta organización en la que se enmarca aquella. Se tendría una visión incompleta de los delitos contra la administración pública, si no se explicare previamente la función social que cumple el Estado en este ámbito. En efecto, lo característico de 
esta clase de delitos, a diferencia de un homicidio, por ejemplo, es la infracción de deberes jurídicos propios de la condición de funcionario estatal y el abuso de poderes públicos que deben ejercitar los órganos de la Administración ${ }^{1}$. Dichos poderes, como es evidente, emanan de la existencia y legitimidad del Estado en la sociedad.

Desde que los seres humanos decidimos voluntariamente dejar el primigenio "estado de naturaleza" para formar una "sociedad civil" a través de un "pacto social", otorgamos ciertos poderes a otras personas para que salvaguarden nuestra vida, libertades, propiedad, etc., eliminando o controlando los peligros que impidan el disfrute de los mismos $^{2}$. Conforme señala Locke: “(...) la finalidad máxima y principal que buscan los hombres (...) sometiéndose a un gobierno, es la de salvaguardar sus bienes (...)"3. En base a este pacto social, los individuos por igual se hacen acreedores de derechos subjetivos que en el previo "estado de naturaleza" no tenían, y que generan una protección de su persona frente a agresiones de terceros ${ }^{4}$. En esta lógica, la función del Estado consiste en establecer los límites del poder frente a la esfera de la libertad individual. El Estado circunscribe su actuación a garantizar un ámbito social de autodeterminación individual, más allá de lo que realmente sucede con los derechos subjetivos en la dinámica social ${ }^{5}$.

La función descrita era la función que cumplía el denominado Estado liberal puro ${ }^{6}$, el cual nació entre los siglos XVIII y XIX en contraposición al Estado absolutista anterior, en donde el soberano ejercía su poder de manera prácticamente ilimitada ${ }^{7}$. Como bien afirma González Moreno, en el Estado liberal burgués del siglo XIX la sociedad era antagónica al Estado, tanto en sus intereses como en su ámbito de actividad $^{8}$. Aquí el Estado se sobrepone a la sociedad civil para regular los intereses individuales que dieron origen a esta.

En el modelo de Estado liberal puro, el Estado aparece como un mal necesario y su actuación solo debe enmarcarse en la protección de la libertad de los individuos. Aquí el Estado tendría solo una función negativa frente a los derechos de la persona;

1 Cfr. Fernando VÁsquez-Portomeñe Seijas. Los delitos contra la administración pública. Teoría general. Instituto Nacional de Administración Pública. Santiago de Compostela, Universidad de Santiago de Compostela, 2003, p. 349.

2 Cfr. John Locke. Segundo Tratado sobre el gobierno. Un ensayo sobre el verdadero origen, alcance y fin del gobierno civil. Madrid, Biblioteca Nueva, 1999, p. 123.

3 Ibídem.pp. 119 y ss.

4 Cfr. J.J. Rousseau. El contrato social, Madrid, EDAF, 1989, pp. 53-55.

5 Cfr. Beatriz González Moreno. El Estado social, naturaleza jurídica y estructura de los derechos sociales. Madrid, Civitas, 2002, p. 38.

6 Ibídem.

7 Cfr. Encarnación Carmona Cuenca. El Estado Social de Derecho en la Constitución. Madrid, Consejo Económico y Social, 2000. p. 26.

8 Ibídem. 
es decir, solo pretende evitar que en el ejercicio de los mismos se vean amenazados por ataques externos.

Una concepción diferente de Estado fue la formulada posteriormente en el siglo XX por la mayor parte de las Constituciones europeas tras la Segunda Guerra Mundial ${ }^{9}$ y que surgió en Europa a mediados del siglo XIX para reivindicar el Estado de Derecho frente a la dictadura fascista y dotar de un contenido social al Estado de Derecho -originalmente formulado por el liberalismo- que atenúe los efectos de desigualdad entre las clases a que había conducido el Estado liberal ${ }^{10}$. Este es el concepto del Estado Social de Derecho, en virtud del cual el Estado ya no es un simple guardián de las libertades y derechos de los individuos formalmente reconocidos, sino que es el llamado a posibilitar o promover la realización efectiva de los derechos fundamentales del individuo.

En el Estado Social de Derecho los poderes públicos asumen la responsabilidad de proporcionar a los individuos las prestaciones y servicios públicos adecuados para satisfacer sus necesidades ${ }^{11}$. Según García Pelayo, dichas prestaciones estatales incluyen la seguridad de los distintos aspectos vitales en la sociedad, la prevención de situaciones de necesidad de carácter global, la fijación de un salario mínimo vital, el acceso a puestos de trabajo, la atención a los colectivos más débiles, etc. ${ }^{12}$.

Este modelo de Estado es el que la Constitución Política del Perú de 1993 (Constitución en adelante) -como norma suprema del ordenamiento jurídico- en su artículo $43^{\circ}$ ha erigido explícitamente en el Perú ${ }^{13}$. Según esta norma "la República del Perú es democrática, social, independiente y soberana”. Sobre este punto, el Tribunal Constitucional, como máximo intérprete de la Constitución ${ }^{14}$, ha sostenido lo siguiente:

El Estado social y democrático de derecho no obvia los principios y derechos básicos del Estado de derecho, tales como la libertad, la seguridad, la propiedad privada y la igualdad ante la ley; antes bien, pretende conseguir su mayor efectividad, dotándolos de una base y un contenido material, a partir del supuesto de que individuo y sociedad no son categorías aisladas y contradictorias, sino dos términos en implicación recíproca. Así, no hay posibilidad

9 Cfr. Beatriz González Moreno. Ob. cit., p. 29.

10 Cfr. E. Carmona Cuenca. Ob. cit., p. 32.

11 Cfr. Perez Luño citado por Beatriz González Moreno. Ob. cit., p. 46.

12 Cfr. Beatriz González Moreno. Ob. cit., p. 47.

13 Cfr. Víctor García Toma. La Constitución comentada. Análisis artículo por artículo. Walter GuTIÉRREZ (director). Tomo i. Lima, Gaceta jurídica, 2005. p. 680, quien concluye que el Estado social de Derecho es el modelo de Estado del Perú en virtud del entendimiento conjunto del artículo $3^{\circ}$ y el artículo $43^{\circ}$ de la Constitución.

14 Esto se desprende del artículo $201^{\circ}$ de la Constitución y el artículo $1^{\circ}$ de la Ley n. ${ }^{\circ}$ 28301- Ley Orgánica del Tribunal Constitucional. 
de materializar la libertad si su establecimiento y garantías formales no van acompañados de unas condiciones existenciales mínimas que hagan posible su ejercicio real ${ }^{15}$.

Desde nuestro punto de vista y sin pretender abordar profundamente el tema, el Estado no solo reconoce los derechos fundamentales de la persona, sino que pretende efectivizar los mismos creando condiciones adecuadas para su ejercicio. Como bien afirma García Toma, el Estado social y democrático de Derecho no obvia los principios y derechos básicos del Estado de Derecho, tales como la libertad, la seguridad, la propiedad privada y la igualdad ante la ley, sino que pretende conseguir que estos sean efectivos ${ }^{16}$. De ello, que el Estado, a través de sus instituciones, tenga un rol activo, con obligaciones positivas, frente a los derechos individuales ${ }^{17}$ garantizando el disfrute de los mismos en condiciones de igualdad. El principio constitucional del Estado Social supone la exigencia de posibilitar el disfrute efectivo por parte de los ciudadanos de las posiciones jurídicas aseguradas por los derechos fundamentales ${ }^{18}$. Esta posición ha sido recogida por el propio Tribunal Constitucional peruano, cuando sostuvo que “(...) la noción de Estado social y democrático de derecho concreta los postulados que tienden a asegurar el mínimo de posibilidades que tornan digna la vida y, en esas circunstancias, se impone principalmente a los poderes públicos la promoción de esas condiciones"19.

\section{El concepto y función de la administración pública}

Habiendo expuesto los fundamentos de la creación y funcionamiento del Estado en un Estado social de Derecho, podemos sostener que la administración pública aparece como institución creada por el Estado -algunos dirían que es su concreción-20 para servir de mecanismo de conexión entre la sociedad civil y el Estado. El Estado, como ente abstracto, cumple sus fines sociales, antes indicados, a través de la administración pública. La administración pública posibilita que el Estado cumpla sus fines prestacionales.

15 Sentencia del Tribunal Constitucional n. ${ }^{\circ}$ 0008-2003-Ai/TC de 11 de noviembre de 2003. Fundamento 11 .

16 Cfr. Víctor García TOMA. Loc. cit.

17 Es de notar que, desde nuestro punto de vista, los derechos sociales no se diferencian sustancialmente de los derechos individuales, por cuanto aquellos son una ampliación del alcance de estos [Cfr. Germán Bidart CAmpos. Teoría general de los derechos humanos. Buenos Aires, Astrea, 1991, p. 335].

18 Cfr. p. 56.

19 Sentencia del Tribunal Constitucional n. ${ }^{2} 2945-2003-$ AA/TC de 20 de abril de 2004. Fundamento 26 .

20 Cfr. Jacques Chevallier. La ciencia administrativa. México, Fondo de Cultura Económica, 1983, p.31. 
Ahora, el definir “administración pública” no es tarea fácil, pues ella presenta múltiples dimensiones. Como bien sostiene Gómez Díaz de León, administración pública puede ser entendida en tres sentidos: como "estructura", como "función" o "como disciplina científica" "21. Nos interesa aquí, a efectos de nuestro estudio, abordar las dos primeras definiciones, que son las que desde nuestro punto de vista coadyuvan a entender la intervención penal en estos casos. Respecto a la primera definición, esto es la administración pública como "estructura", esta es entendida en sentido formal u subjetivo, es decir, como el aparato administrativo gubernamental o como el conjunto de organismos y funcionarios que realizan los fines del Estado ${ }^{22}$.

Por otro lado, la administración pública como "función", es entendida en sentido dinámico u objetivo, es decir como el conjunto de conductas humanas o actividades que determinan como se distribuye y ejerce el poder público ${ }^{23}$. Desde esta concepción, la administración pública se identifica con la propia función pública de la administración. Precisamente, lo que diferencia a la administración pública (en sentido dinámico) de cualquier otra institución u organización privada es que detenta el monopolio de la coerción o coacción estatal ${ }^{24}$.

A nuestro juicio, solo el aspecto dinámico u objetivo - de la administración pública como "función"- es válido de cara a la determinación del objeto de tutela en los delitos contra la administración pública. Más adelante analizaremos este tema a profundidad; basta con señalar, por ahora, que es a través de la administración pública (entendida como función pública) que el Estado cumple con su rol o función social constitucional.

Desde un punto de vista constitucional, la finalidad social específicamente de la administración pública ha sido implícitamente reconocida en el artículo $39^{\circ}$ de la Constitución ${ }^{25}$, el cual señala que “(...) los funcionarios y servidores públicos están al servicio de la Nación" ${ }^{26}$.Como sostiene Asúa Batarrita, "más allá de la prestación de los servicios de interés general, las instituciones públicas a través de sus agentes,

21 Cfr. Carlos Gómez Díaz De LeOn. Administración pública contemporánea. McGraw-Hill interamericana, México, 1998, p. 22.

22 Cfr. Manuel Amaina, citado en Gómez Díaz De Leon, Carlos. Ob. cit., p. 23.

23 Cfr. Muñoz, A. citado en Carlos Gómez Díaz De Leon. Ob. cit., p. 23.

24 Cfr. Carlos Gómez díaz De León. Ob. cit., p. 37.

25 Además del explícito reconocimiento de la función social del Estado en general según el artículo $43^{\circ}$ de la Constitución, conforme ya explicamos anteriormente.

26 Según el Tribunal Constitucional, dicha disposición constitucional implica que los funcionarios públicos sirven al interés general [Sentencia n. ${ }^{\circ}$ 2235-2004-AA/TC de 18 de febrero de 2005. Fundamento 10]. 
los funcionarios en sentido amplio se convierten en garantes de la viabilidad del ejercicio de los derechos fundamentales" 27.

Así pues, en un Estado social y constitucional de Derecho, la legitimidad de la existencia de la administración pública se ubica en sus fines prestacionales ${ }^{28}$. Como afirma Luciano Parejo, en el Estado Social la administración pública es una pieza clave e insustituible, puesto que a través de ella se da cumplimiento efectivo del interés general ${ }^{29}$. La administración pública representa un complejo de medios materiales y humanos que sirven para la consecución de los fines del Estado ${ }^{30}$. Aquí el ciudadano no ocupa una mera situación de sujeción respecto de la administración y sus intereses, sino que aquel y la realización de sus derechos fundamentales son la razón de ser de esta ${ }^{31}$. Es decir, la administración pública brinda “servicios públicos”.

Nótese que cuando decimos que la administración pública cumple con su función de brindar servicios públicos, estamos utilizando una definición amplia de servicios públicos. Desde nuestro punto de vista, los servicios públicos abarcan tanto la actividad de creación de Derecho, la tutela de derechos a través de los Tribunales de Justicia, la defensa del Estado, la seguridad interior, etc. -que vendrían a ser, según Malaret, "funciones públicas" de la administración, dado que por su propia naturaleza son propias del Estado y no pueden ser llevadas a cabo exclusivamente por privados ${ }^{32}$-; como también la asistencia sanitaria, la educación, el suministro de productos energéticos, el transporte público, las telecomunicaciones, etc.-que serían "servicios públicos en sentido estricto" según Malaret, toda vez que su naturaleza posibilita que sean realizadas también por iniciativa privada ${ }^{33}-$.

Por tanto, el buen o correcto funcionamiento de la administración pública es un interés o valor constitucionalmente protegido, pues pretende garantizar el ejercicio de los derechos fundamentales en condiciones de igualdad. Así lo ha establecido nuestro Tribunal Constitucional cuando dedujo del artículo $39^{\circ}$ de la Constitución

27 Adela Asúa BATARrita. "La tutela penal del correcto funcionamiento de la administración. Cuestiones político criminales, criterios de interpretación y delimitación respecto a la potestad disciplinaria". En: Delitos contra la Administración Pública. Adela Asúa Batarrita (dir.), Bilbao, Instituto Vasco de Administración Pública, 1997, p. 19.

28 Ibídem.

29 Cfr. Luciano Parejo Alfonso. Ob. cit., p. 107.

30 Cfr. Manuel Álvarez Rico y Vicente GonzÁlez-Haba Guisado. Administración y función pública en España. Madrid, Libertarias, 1992, p. 41.

31 Cfr. Luis Miguel Reyna Alfaro. "El bien jurídico protegido en los delitos contra la administración pública”. En: Delitos contra la administración pública. REYNA ALFARO, LuIS Miguel (director). Lima, Jurista Editores, 2009, pp. 250-252.

32 Cfr. Malaret I García E. citado por Pedro Rodríguez López y Ana Sobrino Martínez. Delitos contra la administración pública, Barcelona, Bosch, 2008, p. 25.

33 Ibídem. 
el principio de "buena administración” y sostuvo que “( ...) el buen funcionamiento de la administración pública constituye un bien de índole constitucional” cuya protección podría justificar la intervención del Derecho penal (...)"34.

Esta visión de la administración pública, evidentemente, se contrapone a la concepción, ya superada, de administración pública de un "Estado de Policía" que es el modelo de Estado que erigían las monarquías ${ }^{35}$ o los Estados totalitarios. En estos modelos de Estado, la administración pública estaba por encima de los intereses de los ciudadanos, y estos debían guardarle respeto al estar en una situación de sujeción respecto de aquella ${ }^{36}$. Esta tesis no puede ser amparada en el modelo constitucional actual, dado que la persona humana es el fin supremo de la sociedad y el Estado (Art. $1^{\circ}$ de la Constitución).

Por otro lado, una vez que hemos reconocido el valor constitucional de la existencia de la "administración pública" en la sociedad y su buen funcionamiento, cabe notar que el Derecho está llamado a crear mecanismos que aseguren el cumplimiento de los fines de la administración pública, eliminando y/o corrigiendo disfuncionalidades. En tal sentido, uno de estos mecanismos jurídicos es el Derecho penal, entendido como instrumento de control social para la protección limitada de bienes jurídicos. Sobre esto hablaremos a continuación.

\section{LA INTERVENCIÓN DEL PENAL EN EL ÁMBITO DE LA ADMINISTRACIÓN PÚBLICA}

Luego de exponer de manera abreviada los fundamentos de la intervención del Derecho penal, pasaremos a identificar el bien jurídico genérico protegido por todos los delitos contra la administración pública.

\subsection{El Derecho Penal como mecanismo de protección limitado de bienes jurídicos}

El Derecho penal en tanto instrumento jurídico de mayor estigmatización contra la persona, encontrará legitimidad en función a sus fines preventivos (que propugnan por una expansión de la intervención punitiva del Estado) y garantistas (que propug-

34 Sentencia del Tribunal Constitucional n. ${ }^{\circ}$ 000017-2011-PI/TC de 03 de mayo de 2012. Fundamento 16.

35 Según John Locke. Ob. cit., p. 123 la monarquía es la forma de gobierno en la cual el poder de dictar leyes recae sobre un solo hombre o sus descendientes.

36 Cfr. Luis Miguel Reyna Alfaro, Ob. cit., pp. 249-250. 
nan por la reducción de la propia violencia estatal) ${ }^{37}$. Ambos tipos de fines, aunque en constante conflicto, van de la mano y se complementan entre sí a fin de que la intervención penal resulte constitucionalmente razonable ${ }^{38}$.

Efectivamente, a nuestro juicio, el Derecho penal, en un Estado Constitucional de Derecho, no puede limitarse a retribuir un mal creado por el delincuente. En esta medida, deben descartarse las "teorías absolutas" de la pena, según las cuales, la pena no tendría ningún fin que pueda ser socialmente útil, sino que sería una simple retribución por un hecho delictivo. En un Estado Social y Democrático de Derecho -dentro del cual se enmarca el Derecho penal-debe estar al servicio siempre del ser humano y su dignidad. En este sentido, la norma penal no puede olvidar su anclaje ontológico de protección última del individuo, sin que se niegue la presencia de efectos simbólicos de reafirmación de la vigencia de la propia norma. Como bien señala Alcácer Guirao, “(...) el fin preventivo primordial del Derecho Penal habrá de ser en todo caso la protección de los bienes jurídicos, quedando la protección de la vigencia del ordenamiento, como un fin, si bien legítimo, axiológica y funcionalmente subordinado a aquel" 39 .

Al respecto, cabe mencionar que nuestro Tribunal Constitucional en su sentencia n. ${ }^{\circ} 000014-2006-\mathrm{PI} / \mathrm{TC}$ de 19 de enero de 2007. (Fundamentos 12 y 13 ) ya se ha pronunciado sobre los fines que cumple el Derecho penal en un Estado Constitucional de Derecho y ha descartado la validez de las teorías absolutas de la retribución. Así, en su oportunidad, el Tribunal sostuvo lo que sigue:

(...) Este Colegiado ya ha descartado que se conciba a la retribución absoluta como el fin de la pena. Ello, desde luego, no significa que se desconozca que toda sanción punitiva lleva consigo un elemento retributivo. Lo que ocurre es que la pretensión de que ésta agote toda su virtualidad en generar un mal en el penado, convierte a éste en objeto de la política criminal del Estado, negando su condición de persona humana, y, consecuentemente, incurriendo en un acto tan o más execrable que la propia conducta del delincuente.

Sin embargo, las teorías preventivas, tanto la especial como la general, gozan de protección constitucional directa, en tanto y en cuanto, según se verá, sus objetivos resultan acordes con el principio-derecho de dignidad.

37 Cfr. Jesús M Silva SÁnchez, Aproximación al Derecho Penal contemporáneo. Barcelona, Bosch, 1992 , p. 241 y 242.

38 A este respecto, ver la sentencia del Tribunal Constitucional n. ${ }^{\circ} 00017-2011-\mathrm{PHC} / \mathrm{TC}$ de 3 de mayo de 2012. Fundamentos $6^{\circ}$ al $8^{\circ}$.

39 AlCACER GIRAO. ¿Lesión de un bien jurídico o lesión del deber? Apuntes sobre el concepto RAFAEL material del delito. Barcelona, Atelier, 2003, p. 123. 
Dicho lo anterior, podemos afirmar que el Derecho penal interviene en las conductas que se enmarcan en el funcionamiento de la administración pública, en tanto pretende proteger, mediante efectos preventivos, un bien jurídico-penal (que aún no hemos delimitado) frente a los ataques más graves en su contra.

\subsection{La incriminación de delitos contra la administración pública en la Constitución}

Aun cuando no existe un mandato constitucional expreso y específico de criminalización de conductas que atenten contra el funcionamiento de la administración pública, existen preceptos en la Constitución a partir de los cuales se puede interpretar que el legislador tiene el deber de reprimir penalmente ciertas conductas que afectan el correcto funcionamiento de la administración pública. Así, la Constitución establece lo siguiente:

Artículo $41^{\circ}$. Los funcionarios y servidores públicos que señala la ley o que administran o manejan fondos del Estado o de organismos sostenidos por éste deben hacer declaración jurada de bienes y rentas al tomar posesión de sus cargos, durante su ejercicio y al cesar en los mismos. La respectiva publicación se realiza en el diario oficial en la forma y condiciones que señala la ley.

Cuando se presume enriquecimiento ilícito, el Fiscal de la Nación, por denuncia de terceros o de oficio, formula cargos ante el Poder Judicial.

La ley establece la responsabilidad de los funcionarios y servidores públicos, así como el plazo de su inhabilitación para la función pública.

El plazo de prescripción se duplica en caso de delitos cometidos contra el patrimonio del Estado.

En cuanto al segundo párrafo del artículo citado, se observa que la norma constitucional presupone la existencia de un delito contra la administración pública, cual es el enriquecimiento ilícito de artículo $401^{\circ}$ del Código penal peruano (CP, en adelante), por lo que el legislador no podría eliminar o dejar de tipificar el mismo. En este caso, la propia Constitución es la que obliga al legislador a tipificar este delito.

Asimismo, el párrafo cuarto del citado artículo establece la dúplica del plazo de prescripción para los delitos cometidos por funcionarios públicos contra el patrimonio estatal. Conforme lo ha interpretado la jurisprudencia nacional vinculante, se trata de delitos cometidos por funcionarios públicos, pero que tienen que ver con 
la lesión al correcto funcionamiento de la administración pública, es decir, delitos funcionariales ${ }^{40}$.

Si bien no todo delito funcionarial supone un atentado contra el patrimonio del Estado $^{41}$, algunos de ellos como el peculado (Art. 387 CP) sí lo hacen, por lo que también se deduce de este precepto que existe un mandato al legislador de incriminar penalmente ciertos atentados contra la administración pública. A nuestro juicio, la Constitución exige una dúplica del plazo de prescripción porque asume que deben existir delitos contra la administración pública, algunos de los cuales lesionan el patrimonio estatal.

\section{SOBRE EL BIEN JURÍDICO-PENAL PROTEGIDO EN LOS DELITOS CONTRA LA ADMINISTRACIÓN PÚBLICA}

Como ya se señaló, los bienes jurídicos son aquellos que el Derecho penal debe o pretende proteger en última instancia ${ }^{42}$. La protección de bienes jurídicos legitima la intervención del Derecho penal; sin embargo, para establecer qué función cumple el bien jurídico en la sistemática penal es necesario, primero, darle contenido a dicho concepto.

Aun cuando - como bien señala Schunemann-, en la actualidad, no ha quedado del todo claro y no ha habido consenso doctrinal sobre el concepto de bien jurídico ${ }^{43}$, la doctrina penal suele identificar dos vertientes teóricas para definir el bien jurídico: las "teorías personalistas" y las "teorías del daño social" o "teorías funcionalistas". Según las primeras, el bien jurídico vendría definido por su carácter personalista; es decir, se dota de prioridad valorativa a la persona y su esfera de intereses, contraponiéndolos de manera absoluta con los intereses supra personales tendientes a cumplir alguna función social ${ }^{44}$. De otro lado, la teoría del daño social o funcional aprecia al bien jurídico desde una dimensión social, de tal manera que él representa las condiciones necesarias para la conservación de un orden social ${ }^{45}$.

40 Ver al respecto el Acuerdo Plenario de la Corte Suprema de Justicia n. ${ }^{\circ}$ 1-2020/CJ-116 de 16 de noviembre de 2010 (fundamento $15^{\circ}$ ).

41 Ver al respecto el Acuerdo Plenario de la Corte Suprema de Justicia n. ${ }^{\circ}$ 1-2020/CJ-116 de 16 de noviembre de 2010 (fundamento $14^{\circ}$ ).

42 Cfr. Rafael Alcacer Girao. Ob. cit., p. 126.

43 Cfr. Bernd Schunemann. ¡El Derecho Penal es la última ratio para la protección de bienes jurídicos! Bogotá, Universidad externado de Colombia, 2007, p. 17.

44 Cfr. Rafael Alcacer Girao. Ob. cit., p. 72

45 Cfr. Jesús María Silva SÁnchez. Ob. cit., pp. 268-269. 
En nuestra opinión, el concepto de bien jurídico-penal deberá contener tanto el aspecto ontológico-subjetivo referente al individuo y a la protección y garantía de sus derechos humanos, como el aspecto normativo-objetivo referente a las valoraciones sociales y a los fines preventivos del Derecho penal. El bien jurídico, entonces, es un "objeto valorado", supone una realidad social valorada y regulada por normas jurídicas $^{46}$. Del mismo modo, dicho bien jurídico (vida, integridad, libertad ambulatoria, etc.) es apreciado en tanto cumple una función social, es decir, en tanto posibilita la participación igualitaria en sociedad. Luego, no es la vida como concepto estático lo que se pretende garantizar, sino que su existencia misma depende de su utilidad para las relaciones sociales ${ }^{47}$.

Es decir, aquello que legitima, a fin de cuentas, la intervención penal es la propensión a la satisfacción de necesidades de la persona humana en un contexto social ${ }^{48}$. Desde mi punto de vista, aquello que merece la intervención penal solo se justifica en cuanto maximice la dignidad humana y su libre desarrollo en sociedad. Para esto se tendrá que atender, tanto a los efectos preventivos generales del Derecho penal, como a los fines garantistas que limitan la intervención punitiva del Derecho penal.

Esta combinación del componente subjetivo (personal) y objetivo (dañosidad social) del bien jurídico, también, parece haber sido la concepción adoptada por nuestro Tribunal Constitucional cuando en su oportunidad sostuvo lo siguiente:

Si bien en la identificación de los niveles de protección de los bienes constitucionalmente relevantes es importante evaluar la dañosidad social de las conductas que pongan en peligro o afecten tales bienes, también lo es evaluar, dentro de esta dañosidad social, que el objeto de esta protección penal exprese necesariamente las posibilidades de libre desarrollo del individuo mediante su participación en la sociedad ${ }^{49}$.

La determinación del objeto de protección del tipo penal es esencial para realizar la denominada "interpretación teleológica" que nos permita entender al tipo más allá de la apreciación de su tenor literal o gramatical ${ }^{50}$.

46 Cfr. Rafael Alcacer Girao. Ob. cit., p. 88.

47 Ibídem.p. 90.

48 Comparte esta posición Santiago Mir Puig. "Límites del normativismo en el derecho penal", en Dogmática y criminología. Dos visiones complementarias del fenómeno delictivo. Bogotá, Legis, 2008, p. 380.

49 Sentencia del Tribunal Constitucional n. $.^{\circ} 00012-2006-\mathrm{PI} / \mathrm{TC}$ de 15 de diciembre de 2006. Fundamento $30^{\circ}$.

50 Cfr. Hans-Heinrich Jescheck y Thomas Weigend. Tratado de Derecho Penal. Parte General. $5^{\text {a }}$ ed., Granada, Comares, 2002, p. 166; y Santiago Mir Puig. Derecho Penal. Parte General. $7 \mathrm{ma}$ edición. Barcelona, Reppertor, 2005, p. 169. 


\subsection{Acerca de los bienes jurídicos colectivos}

Luego de haber expuesto nuestra posición respecto de la concepción del Derecho penal y su legitimidad en un Estado Social y Constitucional de Derecho, y de lo que entendemos por bien jurídico-penal protegido, ahora, es oportuno enfocar nuestro análisis en el objeto de protección de los llamados "delitos contra la administración pública". Para ello, creemos que es necesario abordar el análisis de los "bienes jurídicos colectivos", que son la clase de bienes jurídicos que desde nuestro punto de vista están en juego en estos delitos.

Al respecto, la doctrina penal ha distinguido dos vertientes teóricas respecto del entendimiento de los bienes jurídicos colectivos: la "teoría monista" y la "teoría dualista".

\section{a. Teoría monista}

Esta teoría propugna por una supresión de la bifurcación dogmática entre bienes jurídicos individuales y colectivos, puesto que únicamente los primeros serían bienes jurídicos penalmente protegibles ${ }^{51}$.

Dentro de la teoría monista, se han reconocido dos posturas: la teoría monista personalista y la teoría monista social o estatal ${ }^{52}$. Según la teoría monista personalista, solamente los intereses y libertades individuales son merecedores de protección penal, mientras que los bienes colectivos pasarían a tener una jerarquía inferior a ellos debido a su carácter derivativo ${ }^{53}$. Partidario de dicha tesis es Hassemer, quien, como representante de la "escuela de Frankfurt", propuso crear un "Derecho de intervención” distinto al Derecho penal -reservado para protección de bienes jurídicos individuales- para proteger a los bienes jurídicos de naturaleza colectiva ${ }^{54}$.

Dentro de la teoría monista, también, se encuentra la teoría social estatal, según la cual el objeto de protección penal se relaciona directamente con la satisfacción de necesidades de la colectividad antes que las del individuo. Es decir, los bienes jurídicos colectivos al igual que los bienes jurídicos individuales, pretenden evitar lesiones a un orden social establecido ${ }^{55}$.

51 Según Belén Mayo Calderón. Derecho Penal y Tutela de bienes jurídicos colectivos. Revista Peruana de Ciencias Penales. n. ${ }^{\circ}$ 17. 2005, pp. 300-312, aquí se ubican autores como Rodríguez Montañez, Mata Martín, Kindhäuser, entre otros.

52 Esta diferenciación es evidenciada por SUSANA SOTO NAVARRO. La protección penal de los bienes colectivos en la sociedad moderna. Granada, Comares, 2003, pp. 233-239.

53 Cfr. Susana Soto Navarro. Ob. cit., p. 236.

54 Ibídem, p. 237.

55 Ibídem, p. 239. 


\section{b. Teoría dualista}

Esta teoría, en contraposición a la anterior, distingue a los bienes jurídicos individuales de los bienes jurídicos colectivos ${ }^{56-57}$. En esta medida, se elimina entre estos dos tipos de bienes jurídicos toda relación derivativa u orden jerárquico ${ }^{58}$.

Esta teoría fue inicialmente formulada por Tiedemann, para quien los bienes jurídicos colectivos tienen su fundamento en la evolución del sistema de relaciones sociales, generando el surgimiento de diversos intereses no centrados en la persona individualmente considerada, sino en el colectivo social (economía, mercado, etc.) ${ }^{59}$. Los bienes colectivos, por tanto, buscarían proteger ya no relaciones sociales esenciales o básicas dentro del sistema, sino relaciones sociales referidas al propio funcionamiento del sistema social ${ }^{60}$.

De acuerdo con los partidarios de esta teoría dualista, no es que se olvide la dimensión individual de la protección penal, sino que la misma, en todo caso, pasará a ser una ratio legis de la punición. Sobre este punto, nos parece razonable la postura adoptada por Soto Navarro, quien sostiene que más que una relación de jerarquía o derivativa entre bienes jurídicos individuales y bienes jurídicos colectivos, lo que existe es una relación de dependencia recíproca entre ambos ${ }^{61}$.

\section{c. Toma de postura}

En primer lugar, en cuanto a la teoría monista personalista, se podría criticar a la misma que confunde dos planos de análisis distintos, ya que, por un lado, están los intereses y bienes individuales de la persona que, como se explicó anteriormente, siempre serán el fin último de protección de toda norma penal, y por otro lado, están los bienes jurídico-penales colectivos propiamente dichos que son objeto de lesión o puesta en peligro. Como señala Soto Navarro, “(...) la concepción personalista del bien jurídico en su postulado básico no aporta nada nuevo, puesto que nadie discute que el individuo sea el referente último de toda intervención penal (... ${ }^{62}$ ". Una cosa

56 Cfr. Manuel A. Abanto VÁsquez. “Acerca de la teoría de los bienes jurídicos”, en Revista Penal, n. ${ }^{\circ} 18$ (2006), España. En: http://www.uhu.es/revistapenal/index.php/penal/article/viewFile/283/273. Visitado el 25 de setiembre de 2012, p. 6.

57 Según Belén Mayo Calderón. Loc. cit. Aquí se reconocen autores como Tiedemann, Soto Navarro, Bustos Ramírez y Martínez Buján, entre otros.

58 Cfr. Susana Soto Navarro. Ob. cit., p. 241.

59 Ibídem.

60 Cfr. Juan Bustos Ramírez. "Los bienes jurídicos colectivos”. En: Obras completas. Tomo II. Lima, Ara Editores, 2004. Ob. cit., p. 188.

61 Cfr. Susana Soto Navarro. p. 199.

62 Ibídem, p. 238. 
es que el correcto funcionamiento de la administración pública tenga su fundamento último en la satisfacción de necesidades e intereses individuales, y otra distinta es que dichos intereses o necesidades sean el criterio rector para determinar el desvalor de resultado del delito o el carácter individual colectivo del bien jurídico.

Por otro lado, la crítica que se ha formulado a la teoría monista social o estatal es que, en principio, es una teoría que habría sido avalada por el nacionalsocialismo alemán de la Escuela penal de Kiel y que daría lugar a una instrumentalización del individuo al servicio de la colectividad ${ }^{63}$. En efecto, teniendo como referente el modelo de Estado Social y Constitucional de Derecho, no se debería caer en una concepción colectivista pura del bien jurídico que olvide la dimensión individual de la persona humana como fundamento del ordenamiento jurídico.

A nuestro juicio, la teoría dualista es la que propone un entendimiento del bien jurídico colectivo e individual adecuado. En nuestra opinión, la distinción entre bienes jurídicos individuales y colectivos responde a su distinta función social. En contraste con los bienes jurídicos individuales, los bienes jurídicos colectivos son aquellos que tienen la función primordial de ser aprovechados por la sociedad en su conjunto. Es decir, ninguna persona puede ser excluida del aprovechamiento del bien jurídico y su aprovechamiento individual no impide ni obstaculiza el aprovechamiento por parte de otros ${ }^{64}$. Asimismo, los bienes jurídicos colectivos no pueden dividirse conceptual, fáctica o jurídicamente y atribuir individualmente en porciones ${ }^{65}$. Desde luego, no puede decirse que cada persona disfruta de una parte de la "correcta gestión del patrimonio público", sino que toda la sociedad en abstracto aprovecha de la totalidad de dicho bien jurídico.

\subsection{Clasificación de los bienes jurídicos colectivos}

La doctrina penal ha realizado una clasificación de los bienes jurídicos de naturaleza colectiva. Así, el Prof. Bustos Ramírez identifica dentro de esta categoría a los bienes jurídicos institucionales, los colectivos (propiamente dichos) y los de control ${ }^{66}$.

En primer lugar, los bienes jurídicos institucionales son aquellos referidos a la preservación de determinadas instituciones básicas (procedimientos de solución de conflictos) para el funcionamiento del sistema (administración de justicia, administración pública, etc.). Por su parte, los bienes jurídicos colectivos son aquellos que se refieren a la satisfacción de necesidades de carácter macro social y/o macro económico (salud pública p.ej.). Por último, los bienes jurídicos de control son aquellos

63 Ibídem.

64 Ibídem., p. 244.

65 Ibídem.

66 Cfr. Juan Bustos Ramírez. Los bienes jurídicos colectivos. Ob. cit., p. 192. 
referidos a la propia organización del aparato estatal, para que este pueda cumplir con su función de control social (seguridad interior y exterior) ${ }^{67}$.

Al respecto, debe tenerse presente que los bienes jurídicos institucionales -que son los que nos interesa analizar principalmente para nuestra investigación- no protegen a las instituciones como tales de manera aislada de los intereses sociales, sino que -como bien ha reconocido Bustos Ramírez- están al servicio de los denominados bienes jurídicos colectivos (en estricto), esto es, los referidos a la satisfacción de necesidades de carácter social y/o económico. Los bienes jurídicos institucionales aseguran, mediante procedimientos formalizados (instituciones) el ejercicio efectivo de los derechos e interrelaciones de la personas ${ }^{68}$.

En esta medida, los delitos funcionariales no protegen a la administración como institución en sí misma, sino a la función pública que ella cumple para satisfacer las necesidades sociales. Precisamente, a continuación explicaremos el contenido del bien jurídico colectivo de naturaleza "institucional” que protegen los delitos contra la administración pública.

\subsection{Delimitación del bien jurídico protegido en los delitos contra la administración pública}

Los delitos contra la administración pública protegen un bien jurídico institucional denominado "correcto funcionamiento de la administración pública". La administración pública se protege penalmente en tanto "función administrativa" que resulta indispensable para el funcionamiento del sistema social. Como se adelantó, aquí no se protege a los órganos administrativos como tales, sino a la función pública que supone vías procedimentales de actuación administrativa (instituciones) para que todos y cada uno de los miembros de la sociedad puedan resolver sus conflictos sociales o efectivizar sus intereses ${ }^{69}$.

Sobre el particular, es necesario hacer notar características comunes en todos los delitos contra la administración pública, pues consideramos que guardan un mismo fundamento de legitimación. Y es que lo característico de esta clase de delitos es la infracción de deberes jurídicos propios de la condición de funcionario estatal y el abuso de poderes públicos que deben ejercitar los funcionarios de la administración ${ }^{70}$. Es decir, todo delito funcionarial supondría un abuso de las competencias que

67 Ibídem., p. 193.

68 Cfr. Juan Bustos Ramírez. Manual de Derecho Penal. Parte Especial. Barcelona, Ariel, 1991, p. 365 y 366.

69 Ibídem., p. 366.

70 Cfr. Fernando Vásquez-Portomeñe Seijas. Ob. cit., p. 349. 
la función pública otorga al funcionario, lo cual si se reproduce de manera masiva perjudicaría el correcto funcionamiento de la administración pública.

Conforme explicaremos con más detenimiento posteriormente, consideramos que el "correcto funcionamiento de la administración pública" es un "bien jurídico general" en los delitos funcionariales (o ratio legis desde nuestro punto de vista) que, luego, es concretizado en cada figura delictiva, constituyéndose, así, el auténtico "bien jurídico específico" del delito funcionarial respectivo. Desde nuestro punto de vista, la identificación del bien jurídico general es una tarea útil, pues, además de ayudar al mejor entendimiento y sistematización político-criminal de estos delitos, puede tener consecuencias prácticas a la hora de determinar concretamente la pena cuando se comete algún específico delito contra la administración pública ${ }^{71}$. Sobre esto abundaremos más adelante.

En efecto, para dar un panorama de la problemática planteada sobre este punto, se ha reconocido en la doctrina penal principalmente cuatro teorías en cuanto al objeto de protección en los delitos contra la administración pública: a) la teoría del quebrantamiento de las expectativas en la administración pública, b) la teoría protección de la fidelidad al Estado (deber del cargo), c) la teoría de la buena imagen, dignidad o prestigio de la administración pública y d) la teoría del correcto funcionamiento o la funcionalidad de la administración pública.

\section{a. Teoría del quebrantamiento de las expectativas en la administración pública}

Respecto de la teoría del quebrantamiento de expectativas en la administración pública, habría que señalar, primero, que la misma no reconoce como objeto de tutela a un bien jurídico conforme lo hemos definido precedentemente. Esta teoría, cuyo máximo exponente es el Prof. Jakobs, tiene como presupuesto que el Derecho penal no protege bienes jurídicos, sino las expectativas normativas de la sociedad ${ }^{72}$. En este sentido, el objeto de prohibición de los delitos contra la administración pública sería la decepción de la expectativa de que una "institución" básica de la sociedad, como lo es el "deber de velar por la sujeción a la ley de aquellos que están vinculados a la administración pública", funcione adecuadamente ${ }^{73}$. Es decir, en esta lógica, los delitos contra la administración pública, en tanto "delitos de infracción de deber"74,

71 Cfr. Carlos Martínez-Bujan Perez. Derecho Penal económico y de la empresa. Parte General. Valencia, Tirant lo Blanch, 2007, p. 163.

72 Nos remitimos en este punto a lo señalado supra respecto a la teoría de la pena formulada por el Prof. GÜNTHER JAKOBS.

73 Cfr. GÜNTher Jakobs, citado por Fernando VÁsquez-Portomeñe Seijas. Ob. cit., p. 35.

74 Cfr. GÜNTHER JAKobs. Derecho Penal. Parte General. Fundamentos y teoría de la imputación. Madrid, Marcial Pons, 1997, p. 266 y 267 para quien los delitos de infracción de deber se fundamentan en la existencia de instituciones positivas que crean un estatus especial en el autor, imponiéndole deberes especiales de actuación. 
se centrarían en asegurar las expectativas sociales de que los funcionarios cumplan con su deber de observar las normas estatales para una correcta administración de las funciones públicas ${ }^{75}$.

\section{b. Teoría de la protección de la fidelidad al Estado ("deber del cargo")}

La teoría que plantea que la tutela penal en los delitos contra la administración pública recae sobre la fidelidad al Estado o el deber de funcionario en su cargo público fue originalmente formulada en Alemania ${ }^{76}$. Según esta teoría, el injusto de los delitos de funcionarios se fundamenta en la infracción de un deber específico de la función pública $^{77}$, de tal manera que la conducta ilícita del funcionario, considerado como sometido a la estructura estatal, quiebra la confianza depositada en él. Es decir, considera a los delitos funcionariales como una traición, una deslealtad en contra del Estado y su estructura. Lo que plantea esta teoría es reducir el fundamento de punición de estos delitos a un incumplimiento de los deberes administrativos que se le imponen en el ejercicio del cargo, es decir, se tiene una lectura formal del bien jurídico protegido. Es por ello que algunos autores como Rodríguez Muñoz, Jaso Roldán y Rodríguez Devesa, en España, señalan que los delitos funcionariales son en puridad infracciones administrativas elevadas a la categoría de delitos ${ }^{78}$.

\section{c. Teoría de la buena imagen, dignidad o prestigio de la administración pública}

Esta postura plantea considerar al prestigio, dignidad o buena imagen de la administración pública como el bien jurídico genérico protegido por estos delitos. El comportamiento irregular del funcionario público constituiría, entonces, un atentado contra el prestigio que toda la administración pública debería tener de cara a sus administrados ${ }^{79}$.

En esta lógica, los delitos funcionariales deben ser perseguidos y sancionados en tanto que enlodan la reputación de la administración frente a la población. La razón o fundamento de la protección penal, entonces, no se ubica en la fuente del prestigio o buena imagen de la administración (el correcto desempeño del cargo público), sino al prestigio, dignidad o buena imagen en $\mathbf{s i}^{80}$.

75 Cfr. José Antonio Caro John. "Algunas consideraciones sobre los delitos de infracción de deber", en Anuario de Derecho Penal. Asociación Peruana de Derecho Penal, 2003. p. 60, 61 y 65.

76 Según Carlos Guillermo Castro Cuenca. Ob. cit., p. 92. Aquí se ubican autores notables como Binding, Merkel, Mezger y Welzel.

77 Cfr. Norberto J. De la Mata Barranco. "Sentido y límites de la sanción penal de conductas de corrupción pública”, en Delitos contra la administración pública. Luis Miguel Reyna Alfaro (dir.), Lima, Jurista Editores, 2009. p. 45.

78 Así lo hace notar Carlos Guillermo Castro Cuenca. Ob. cit., p. 93.

79 Cfr. Adela Asúa Batarrita. Ob. cit., pp. 20-22.

80 Ibídem. 


\section{d. Teoría del correcto funcionamiento o la funcionalidad de la administración pública}

Por último, la doctrina mayoritaria actualmente viene siendo partidaria de la teoría del correcto funcionamiento o funcionalidad de la administración pública como bien jurídico penal genérico tutelado por los delitos funcionariales. Según esta teoría, lo que se tutela es la función o tarea constitucional de la administración pública, que consiste en servir con eficacia, coordinación, imparcialidad, jerarquía y objetividad, o legalidad -como concepto envolvente de los anteriores principios-a los intereses sociales generales ${ }^{81}$. Es decir, se entiende a la administración pública como un bien jurídico de tipo funcional y no estático. Se protege a la administración pública, no porque esta merezca ello per se por su propia existencia, sino porque cumple determinados fines sociales amparados por la Constitución. En puridad, estamos ante la protección penal de la "función pública"82-83.

Cabe notar que esta posición sobre el bien jurídico protegido en estos delitos, también ha sido la recogida por el Tribunal Supremo español en su sentencia de 10 de julio de 1995, en la que se señaló que “(...) el bien jurídico protegido es el recto y normal funcionamiento de la administración, con sujeción al sistema de valores instaurado en la C.E. y en consideración a los artículos 103 y 106 que sirven de punto de partida para cualquier actividad administrativa" 84 .

\section{e. Toma de postura}

A nuestro juicio, en primer lugar, no se puede compartir la teoría del quebrantamiento de las expectativas en la administración pública, puesto que, como ya se dijo, el Derecho penal no puede dejar de proteger principalmente bienes jurídicos; además, esta teoría olvida o infravalora el aspecto social de la administración pública, centrando el objeto de prohibición en los deberes funcionariales. Creemos que, en fecto, existe una expectativa de los ciudadanos en que los funcionarios cumplan con sus deberes normativos; sin embargo, ello no puede ser el eje central del injusto en los delitos contra la administración pública. Aquí, en semejanza a la teoría del "deber de cargo", se relega la relación Estado-ciudadano para centrarse primordialmente

81 Esta opinión es la síntesis de la posición de Bernardo FeiJóo SAnchez. "Delitos contra la Administración Pública en el Código Penal Español de 1995: Consideraciones generales, nuevas figuras delictivas y modificación de otras conocidas”, en Revista Peruana de Ciencias Penales. n. ${ }^{\circ}$ 7/8. p. 700 y Norberto J. De la Mata Barranco. Ob. cit., p. 50.

82 Cfr. Bernardo Feijóo Sanchez. Loc. cit., y Pedro Rodríguez Lopez, y Ana Sobrino Martínez. Loc. cit.

83 Esta consideración también se condice con lo señalado por el Tribunal Constitucional en su sentencia n. ${ }^{\circ}$ 00017-2011-AI/TC de 3 de mayo de 2012 (fundamento $15^{\circ}$ ), en donde el Tribunal sostuvo que la protección penal del correcto desempeño de la función pública venía reforzado constitucionalmente.

84 Sentencia del Tribunal Supremo n. ${ }^{\circ} 798 / 1995$. 
en la relación funcionario-Estado. Como señalamos antes, esto es incompatible con el modelo de Estado Social de Derecho del Perú.

Por otro lado, respecto de la teoría de la fidelidad al Estado ("deber del cargo"), nosotros discrepamos de su propuesta en vista de las siguientes consideraciones: primero, la teoría del "deber del cargo" tendría tintes autoritarios incompatibles con el modelo de Estado Social y Democrático de Derecho, puesto que se centraría exclusivamente en la relación funcionario público-Estado, postulando un Estado por encima de los intereses sociales e individuales y, por ende, dejando de lado la labor prestacional y social de la administración pública ${ }^{85}$. Segundo, un injusto penal no puede reducirse a un mero añadido a la infracción administrativa. Lo que se plantearía aquí es una accesoriedad administrativa absoluta del Derecho penal, vaciando de contenido material propio al bien jurídico-penal protegido e imposibilitando la limitación de la intervención penal ${ }^{86}$. Por último, la teoría de la mera infracción del deber no podría explicar suficientemente la presencia de delitos encuadrados en la sistemática de los delitos contra la administración pública que tienen como sujetos activos a particulares no funcionarios públicos, pero que contribuyen a afectar la prestación de funciones públicas objetivamente consideradas (cohecho activo y tráfico de influencias, por ejemplo) $)^{87}$.

En lo concerniente a la teoría del prestigio, buena imagen o dignidad de la administración pública, a nuestro juicio, la misma no puede ser compartida, puesto que desatiende el rol de los órganos estatales al servicio del ciudadano. Esta teoría es inaceptable en un Estado Social y Democrático de Derecho, ya que ofrece una visión autoritaria de la administración, al considerarla como fin en sí misma ${ }^{88}$. De igual manera, la utilización de términos como "el prestigio" o "la dignidad" no esclarecen el objeto de protección, en la medida en que son criterios de concreción inseguros, genéricos y vagos que no ayudan a dilucidar qué clase de conductas merecen la intervención penal ${ }^{89}$. Por último, el prestigio, la dignidad o la buena imagen no pueden ser objeto central de protección penal, pues ellos solo deberían ser consecuencia del verdadero objeto de protección, cual es el correcto funcionamiento de la administración pública. El sostener que se busca proteger per se el prestigio o buena imagen de la administración podría justificar la impunidad de actuaciones irregulares en el ejercicio del cargo público que pasan inadvertidas a los ojos de la opinión pública.

85 Cfr. Eduardo Demetrio Crespo. "Corrupción y delitos contra la administración pública”, en $L a$ corrupción, aspectos jurídicos y económicos. EDUARDO FABIÁN CAPARRÓs (coordinador). Salamanca, Ratio Legis, 2000, p. 69.

86 Cfr. Norberto J. De La Mata Barranco. Ob. cit., p. 46.

87 Ibídem., p. 48.

88 Comparte esta crítica De La Mata Barranco, Norberto J. Ob. cit., p. 49.

89 Así, Asúa BatArrita. Ob. cit., p. 22. 
En nuestra opinión, la teoría más acertada es la teoría del correcto funcionamiento o funcionalidad de la administración pública. En efecto, con esta definición del bien jurídico se toma en consideración primordialmente la relación existente entre administración estatal y ciudadano, reconociendo a este último como fundamento de la actividad prestacional de aquella. Esta posición también ha sido compartida por la Prof. Asúa Batarrita, cuando señala que "la materia necesitada de protección se refiere a la preservación de la forma de actuación de la Administración conforme a sus fines y en el sometimiento a aquellos principios que informan el procedimiento en la adopción de decisiones de su competencia ${ }^{90}$ ". Así, la corrección de la administración pública se evalúa en el plano axiológico a partir de los principios constitucionales que informan la actuación administrativa y no en base a intereses propios de la administración como ente supraindividual.

Asimismo, compartimos la posición del Prof. De la Mata, cuando sostiene que no solo estamos ante un concepto objetivo (función pública) y no subjetivo (administración pública como estructura orgánica estatal) de la administración, sino ante un concepto prestacional de esta, que exige delimitar su fines y atender a los principios que inspiran su actuación ${ }^{91}$. Efectivamente, el reconducir el concepto penal de la administración pública a la función pública, nos obliga a desechar una concepción puramente formal de ella, que solo atendería a la naturaleza del órgano estatal (judicial, ejecutivo, legislativo, etc.) dentro del cual se comete la irregularidad del funcionario ${ }^{92}$.

\section{- Conceptualización de la función pública}

Así pues, el concepto de administración pública debe ser reconducido al ejercicio de la función prestacional pública. Por ello, los delitos que atentan contra la administración púbica - tal y como la hemos concebido- tienen como rasgo distintivo que se cometen en el ejercicio de la función pública ${ }^{93}$. Sin embargo, ¿qué se entiende por función pública? En la doctrina penal, existen diversas concepciones de la función pública: primero, la concepción material teleológica; segundo, la concepción formal, y tercero, la concepción ecléctica o mixta.

La concepción material teleológica señala que función pública es aquella que tiene por finalidad el interés colectivo o el bien común ${ }^{94}$. Dentro de esta concepción se

90 Ibídem., p. 21.

91 Cfr. Norberto J. De la Mata Barranco. Ob. cit., p. 50.

92 Esta opinión es compartida por R. REVOllo VARGAS. Notas y consecuencias de una lectura constitucional del bien jurídico protegido en el T. XIX, L. II. del Código Penal español. Homenaje al Dr. Marino Barbero Santos. Volumen I. Cuenca, Universidad de Castilla-La Mancha/Universidad de Salamanca, 2001, p. 553.

93 Así lo afirma Soto NaVARro. Loc. cit.

94 Cfr. Fidel Rojas Vargas. Delitos contra la administración pública. Lima, Grijley, 2007, p. 25. 
encuentran dos tesis: la estricta y la extensiva. Según la primera, función pública es la función que, siendo ejercida por un ente perteneciente a la estructura del Estado, tiene por finalidad el bien común o el interés general colectivo, mientras que, la segunda, sostiene que siempre que se cumpla con una finalidad colectiva social, la función pública puede desempeñarla un ente privado o estatal (público) ${ }^{95}$.

Una concepción teleológica intermedia entre la estricta y la extensiva es la formulada por el Prof. Muñoz Conde, quien define la función pública como aquella proyectada al interés colectivo o social y realizada por órganos estatales o instituciones que por delegación del Estado coopera a los fines de este sin formar parte de su burocracia (órganos paraestatales) ${ }^{96}$. Es decir, no se limita a los entes que estén incorporados a la burocracia estatal, sino también aquellos entes que por delegación de este cumplen funciones sociales. Función pública, por tanto, también podría ser la ejercida por los concesionarios de ciertos servicios públicos especiales.

La concepción formal, por su parte, sostiene que función pública será aquella que es desempeñada por un ente que está sujeto a un régimen jurídico público de actividades. A esta posición se adscribe, por ejemplo, Queralt, quien sostiene que la función pública es aquella desempeñada por una entidad pública sometida al Derecho público; por tanto, si la entidad pública está sometida al Derecho privado, la función que lleve a cabo será siempre privada ${ }^{97}$.

A nuestro juicio, las tesis formal y teleológica estricta no pueden ser compartidas, puesto que nuestro ordenamiento jurídico-penal, en virtud del inciso $3^{\circ}$ y $4^{\circ}$ del artículo $425^{\circ} \mathrm{CP}^{98}$-que da presupuestos materiales para la definición de funcionario público- niega la posibilidad de avalar las mismas. Nótese que es importante tomar

95 Ibídem., p. 26.

96 Así lo afirma Inés Olaizola Nogales. "Concepto de funcionario público a efectos penales", en Delitos contra la Administración Pública. Adela Asúa BATARRITA (dir.). Bilbao, Instituto Vasco de Administración Pública 1997, p. 79.

97 Ibídem.

98 "Artículo 425. Funcionario o servidor público "Son funcionarios o servidores públicos:

"1. Los que están comprendidos en la carrera administrativa.

"2. Los que desempeñan cargos políticos o de confianza, incluso si emanan de elección popular. "3. Todo aquel que, independientemente del régimen laboral en que se encuentre, mantiene vínculo laboral o contractual de cualquier naturaleza con entidades u organismos del Estado, incluidas las empresas del Estado o sociedades de economía mixta comprendidas en la actividad empresarial del Estado, y que en virtud de ello ejerce funciones en dichas entidades u organismos.

" 4 . Los administradores y depositarios de caudales embargados o depositados por autoridad competente, aunque pertenezcan a particulares.

"5. Los miembros de las Fuerzas Armadas y Policía Nacional.

"6. Los designados, elegidos o proclamados, por autoridad competente, para desempeñar actividades o funciones en nombre o al servicio del Estado o sus entidades.

"7. Los demás indicados por la Constitución Política y la ley". 
en cuenta la definición penal de funcionario público para conceptualizar a la "función pública", porque para ser funcionario público a efectos penales es necesario cumplir dos requisitos: 1) incorporación heterónoma a la función pública y 2) posibilidad de participar en la "función pública". Luego, la definición de "función pública" a efectos penales no puede ser más restrictiva que la definición penal de funcionario público, ya que todo funcionario público ejerce funciones públicas.

En efecto, según el inciso $3^{\circ} \mathrm{del}$ art. $425^{\circ} \mathrm{CP}$, a efectos penales, para ser funcionario público no interesa la naturaleza jurídica del régimen bajo el que se halle el funcionario (privado o público), por lo que mal puede sostenerse que función pública es la que solo se ejerce por entes regulados por el régimen de Derecho público (tesis formal). Asimismo, el inciso $4^{\circ}$ del art. $425^{\circ} \mathrm{CP}$ establece que son considerados funcionarios públicos los administradores y depositarios de caudales embargados o depositados por autoridad competente, por lo que se entiende que no es necesario que los mismos estén adscritos al aparato burocrático estatal (como sí lo exigen las tesis ecléctica y teleológico estricta).

Del mismo modo, creemos que la tesis teleológica extensiva resulta demasiado amplia para definir a la "función pública", pues permitiría abarcar a las actividades de diversas empresas privadas que cumplen una función prestacional importante en la sociedad (piénsese, por ejemplo, en algunos supermercados). Si se siguiese esta teoría, se correría el riesgo de adjetivar como "público" una inmensa variedad de actividades que en la actualidad, debido al modelo de economía social del libre mercado, se encuentran en manos de privados.

Por ello es que -sin tratar de ser exhaustivos en este problemática dogmático-penalcreemos que la tesis más razonable es la tesis teleológica intermedia. Esta permitiría comprender, a efectos penales, como función pública a aquellas actividades que son realizadas por instituciones o empresas públicas adscritas al régimen de sociedades privadas o concesionarios privados que cumplen determinados servicios públicos especiales. En estos casos, como bien señala el Prof. Abanto Vásquez, no todos los que trabajen en estas sociedades privadas serán considerados funcionarios públicos a efectos penales, sino solo aquellos que ejercen funciones públicas dentro de ellos, estos es, los administradores y directores de ellas ${ }^{99}$.

En este sentido, siguiendo al Prof. Abanto Vásquez, el concepto penal de "función pública" como aspecto central del bien jurídico protegido por los delitos contra la administración pública, desde nuestro punto de vista, incluiría las siguientes actividades: las actividades tradicionales de la administración estatal, los servicios públicos prestados de manera delegada por particulares no insertados en el aparato

99 Cfr. Manuel Abanto Vásquez. Los delitos contra la administración pública en el Código Penal peruano. Lima, Palestra, 2003, p. 31. 
burocrático del Estado, y las actividades de entidades públicas bajo el régimen del sector privado ${ }^{100}$.

En efecto, el concepto de bien jurídico-penal como "correcto desempeño de la función pública" o "correcto funcionamiento de la administración pública" es el que mejor se adecúa a la definición de bien jurídico-penal que hemos establecido anteriormente, toda vez que propone un concepto de administración pública o de función pública orientado a los valores de la Constitución y a la garantía de los derechos e interés de la persona humana mediante la recepción de servicios públicos por parte del Estado.

No cabe duda de que la función pública y su adecuado ejercicio son un interés o valor constitucionalmente protegido. Dicha protección penal, en este ámbito, se ve influida y reforzada por las normas constitucionales, toda vez que, si bien nuestra Constitución no ha reconocido explícitamente los principios que son parámetro de actuación de la administración pública- a comparación de la Constitución española ${ }^{101}$ por ejemplo-, del artículo $39^{\circ}$ de la Constitución se ha deducido el principio genérico de "buena administración” en la función pública.

\subsection{El "correcto funcionamiento de la administración pública" como bien jurídico general o ratio legis}

Ahora, una de las críticas que se le ha formulado a la teoría del "correcto funcionamiento de la administración pública” es que este concepto es una noción muy amplia y abstracta que no permitiría interpretar cabalmente cada tipo penal ${ }^{102}$. Desde nuestro punto de vista, dicha crítica sería infundada, puesto que lo que se identifica en el bien jurídico "correcto funcionamiento de la administración pública" es un "bien jurídico general" o "bien jurídico mediato" para todos los delitos contra la función pública, el cual sería útil para lo siguiente: i) entender las razones político-criminales que fundamentan o legitiman la intervención penal en el ámbito de la administración pública; ii) cumple una función de sistematización de todos los tipos penales funcionariales específicos; y iii) puede servir como criterio a tomar en cuenta para medir la gravedad del hecho y determinar la pena concreta, en la medida que el delito puede incidir mediatamente sobre el "correcto funcionamiento de la administración pública”, además de menoscabar el bien jurídico directamente protegido ${ }^{103}$.

100 Ibídem., p. 30 y 31.

$101 \mathrm{El}$ artículo $103^{\circ}$ numeral $1^{\circ}$ de la Constitución española establece que "la Administración Pública sirve con objetividad los intereses generales y actúa de acuerdo con los principios de eficacia, jerarquía, descentralización, desconcentración y coordinación, con sometimiento pleno a la Ley y al Derecho".

102 En este sentido, Susana Soto Navarro, Ob. cit., p. 265

103 Cfr. Carlos Martínez-Bujan Perez. Ob. cit., pp. 162 y 163. 
Creemos que, como sostiene Martínez-Buján, el bien jurídico mediato en puridad no sería propiamente un bien jurídico-penal, por lo menos no como tradicionalmente ha sido entendido por la doctrina penal, sino una ratio legis o fundamento políticocriminal de la incriminación ${ }^{104}$ que, en todo caso, es útil para categorizar grupos de delitos concretos así como para incidir en la determinación de la pena. No obstante, en nuestra opinión, el bien jurídico mediato no constituye el criterio de determinación del desvalor de resultado del injusto penal ni contribuye a realizar una función hermenéutica del tipo penal ${ }^{105}$.

De esta manera, el bien jurídico general o mediato "correcto funcionamiento de la administración pública" debe ser concretizado en un "bien jurídico específico", dependiendo del determinado tipo penal que se analice. Conforme establece De la Mata Barranco, "la alusión al correcto funcionamiento de la Administración, bien jurídico categorial o finalidad tuitiva común según diferentes terminologías, constituye una referencia genérica y poco indicativa del contenido sustancial del injusto $(\ldots)^{106}$ "

El núcleo del injusto de cada tipo penal funcionarial deberá concretarse a partir de las características esenciales de la actividad funcionarial administrativa de que se trate ${ }^{107}$. Este "bien jurídico específico", "bien jurídico representante”, "bien jurídico inmediato", "objeto de tutela" o "bien jurídico propiamente dicho" sería el que cumple la función interpretativa de cada tipo penal y sería el que es lesionado o puesto en peligro por la conducta típicamente antijurídica.

Desde nuestro punto de vista, "el correcto funcionamiento de la administración pública" es el bien jurídico mediato protegido por todas las figuras de los delitos contra la administración pública. Dicho bien jurídico tiene naturaleza colectiva, como hemos explicado precedentemente, pero se concreta en un determinado objeto de tutela o bien jurídico inmediato o específico. El "correcto funcionamiento de la administración pública" es el bien jurídico mediato tutelado por todos los delitos contra la administración pública como el peculado (malversación), cohechos, colusión, enriquecimiento ilícito, etc., mientras que el bien jurídico inmediato o bien jurídico propiamente dicho será determinado en función del tipo de delito que se analice; por ejemplo, podrá ser el patrimonio público en el peculado, el principio de imparcialidad en el cohecho, etc.

104 Ibídem., p. 158 y ss.

105 El bien jurídico genérico no posibilitaría, entre otras cosas, la solución del concurso de delitos.

106 Norberto J. De La Mata Barranco. Ob. cit., p. 52. Esta opinión también ha sido compartida por Bernardo Feijóo Sanchez. Delitos contra la Administración Pública en el Código Penal Español de 1995. Ob. cit., p. 702.

107 Cfr. Norberto J. De La Mata Barranco. Loc. cit. 


\section{CONCLUSIONES}

1. El buen funcionamiento de la administración pública -entendida como función pública- es un interés o valor constitucionalmente protegido que se desprende del artículo $39^{\circ}$ de la Constitución y que tiene como finalidad garantizar el ejercicio de los derechos fundamentales de las personas en condiciones de igualdad. En un Estado Social y Constitucional de Derecho, a través de la administración pública se ponen a disposición de la sociedad los respectivos servicios públicos (tutela de derechos a través de los Tribunales de Justicia, defensa del Estado, educación, telecomunicaciones etc.); es decir, a través de ella se da cumplimiento efectivo del interés general.

2. El Derecho penal, en tanto mecanismo limitado de protección de bienes jurídicos a través de la prevención de delitos, constituye un instrumento de suma utilidad para garantizar el correcto funcionamiento de la administración pública. El bien jurídicopenal de naturaleza colectiva-institucional que se protege a través de los delitos funcionariales es el "correcto funcionamiento de la administración pública"; es decir, no se protege a los órganos administrativos como tales, sino a la función pública que supone vías procedimentales de actuación administrativa (instituciones) para que los ciudadanos puedan resolver sus conflictos sociales o efectivizar sus intereses. En nuestra opinión, la teoría más acertada es la teoría del "correcto funcionamiento o funcionalidad de la administración pública", puesto que se toma en consideración primordialmente la relación existente entre administración estatal y ciudadano, antes que la mera relación funcionario-Estado.

3. La función pública, en tanto esencia del bien jurídico-penal protegido por los delitos funcionariales, debe ser entendida, a efectos penales, conforme lo propone la "teoría teleológica intermedia"; es decir, como la función proyectada al interés colectivo o social y realizada por órganos estatales o instituciones que por delegación del Estado cooperan a los fines de este sin formar parte de su burocracia (órganos paraestatales).

4. El "correcto funcionamiento de la administración pública" constituye el "bien jurídico general" o "bien jurídico mediato" en todas las figuras de los delitos funcionariales vinculadas a la corrupción pública. Este "bien jurídico general" se debe concretar en un bien jurídico específico" o "bien jurídico inmediato" que constituirá el auténtico objeto de protección de cada figura delictiva. El "correcto funcionamiento de la administración pública" no constituye el criterio de determinación del desvalor de resultado del injusto penal ni contribuye a realizar una función hermenéutica del tipo penal, sino que solo es una ratio legis o razón político-criminal de la incriminación penal de ciertas irregularidades funcionariales. 


\section{BIBLIOGRAFÌA}

Abanto VÁsquez, Manuel A. Los delitos contra la administración pública en el Código Penal peruano, Lima, Palestra, 2003.

Abanto Vásquez, Manuel A. Acerca de la teoría de los bienes jurídicos. Revista Penal, n. 18 (2006), España. En http://www.uhu.es/revistapenal/index.php/penal/ article/viewFile/283/273. Visitado el 25 de setiembre de 2012.

AlCACER Girao, Rafael. ¿Lesión de un bien jurídico o lesión del deber? Apuntes sobre el concepto material del delito, Barcelona, Atelier, 2003.

Alvarez Rico, Manuel y González-Haba Guisado, Vicente. Administración y función pública en España, Madrid, Libertarias, 1992.

AsÚA BATARRITA, AdELA. "La tutela penal del correcto funcionamiento de la administración. Cuestiones político criminales, criterios de interpretación y delimitación respecto a la potestad disciplinaria", en Delitos contra la Administración Pública, Adela Asúa BatARrita (directora), Bilbao, Instituto Vasco de Administración Pública, 1997.

Bustos Ramirez, Juan. Manual de Derecho Penal. Parte Especial, Barcelona, Ariel, 1991.

Bustos Ramirez, Juan. "Los bienes jurídicos colectivos", en Obras completas. Tomo II. Lima, Ara Editores, 2004.

Carmona Cuenca, Encarnación. El Estado Social de Derecho en la Constitución, Madrid, Consejo Económico y Social, 2000.

CARo John, José Antonio. “Algunas consideraciones sobre los delitos de infracción de deber", en Anuario de Derecho Penal, Lima, Asociación Peruana de Derecho Penal, 2003.

Demetrio Crespo, EduARDo. "Corrupción y delitos contra la administración pública”, en La corrupción, aspectos jurídicos y económicos. EdUARDo FABIÁn CAPARRós (coordinador), Salamanca, Ratio Legis, 2000.

De la Mata Barranco, Norberto J. "Sentido y límites de la sanción penal de conductas de corrupción pública", en Delitos contra la administración pública. LuIs Miguel Reyna Alfaro (director), Lima, Jurista Editores, 2009. 
Feijóo SAnchez, Bernardo. "Delitos contra la Administración Pública en el Código Penal Español de 1995: Consideraciones generales, nuevas figuras delictivas y modificación de otras conocidas", en Revista Peruana de Ciencias Penales n. ${ }^{\circ} 7 / 8$, Lima.

García Toma, Víctor. La Constitución comentada. Análisis artículo por artículo. WALTER GutiÉrRez (director). Tomo i, Lima, Gaceta jurídica, 2005.

GonZÁlez Moreno, BeATriz. El Estado social, naturaleza jurídica y estructura de los derechos sociales, Madrid, Civitas, 2002.

Jakobs, Günther. Derecho Penal. Parte General. Fundamentos y teoría de la imputación, Madrid, Marcial Pons, 1997.

Jescheck, Hans-Heinrich y Weigend, Thomas. Tratado de Derecho Penal. Parte General. $5^{\mathrm{a}}$ ed., Granada, Comares, 2002.

Locke, John. Segundo Tratado sobre el gobierno. Un ensayo sobre el verdadero origen, alcance y fin del gobierno civil, Madrid, Biblioteca Nueva, 1999.

Martínez-Bujan Pérez, Carlos. Derecho Penal económico y de la empresa. Parte General, Valencia, Tirant lo Blanch, 2007.

Mayo Calderón, Belén. "Derecho Penal y Tutela de bienes jurídicos colectivos", en Revista Peruana de Ciencias Penales. n. 17 , Lima, 2005.

Mir Puig, Santiago. Derecho Penal. Parte General. $7^{\mathrm{a}}$ ed., Barcelona, Reppertor, 2005.

Mir Puig, Santiago. "Límites del normativismo en el derecho penal”, en Dogmática y criminología. Dos visiones complementarias del fenómeno delictivo, Bogotá, Legis, 2008.

Olaizola Nogales, InÉs. "Concepto de funcionario público a efectos penales", en Delitos contra la Administración Pública. Adela Asúa Batarrita (dir.), Bilbao, Instituto Vasco de Administración Pública, 1997.

PAREJO Alfonso, LuCIANO. Estado social y administración pública. Los postulados constitucionales de la reforma administrativa, Madrid, Civitas, 1983.

Revollo Vargas, R. Notas y consecuencias de una lectura constitucional del bien jurídico protegido en el T. XIX, L. II. del Código Penal español. Homenaje al Dr. Marino Barbero Santos. Volumen I, Cuenca, Universidad de Castilla-La Mancha/ Universidad de Salamanca, 2001. 
Reyna Alfaro, Luis Miguel. "El bien jurídico protegido en los delitos contra la administración pública", en Delitos contra la administración pública. ReYNa AlFARO, Luis Miguel (dir.), Lima, Jurista Editores, 2009.

RoJas VARGas, FIDEL. Delitos contra la administración pública, Lima, Grijley, 2007.

Rodríguez López, Pedro y Sobrino Martínez, Ana. Delitos contra la administración pública, Barcelona, Bosch, 2008.

Rousseau, J.J. El contrato social, Madrid, EDAF, 1989.

Schunemann, Bernd. ;El derecho Penal es la última ratio para la protección de bienes jurídicos!, Bogotá, Universidad Externado de Colombia, 2007.

Silva SÁnchez, Jesús M. Aproximación al Derecho Penal contemporáneo, Barcelona, Bosch, 1992.

SOTO NAVARRo, SusAna. La protección penal de los bienes colectivos en la sociedad moderna, Granada, Comares, 2003.

VÁsQUEZ-PortomeÑe SEIJAS, Fernando. Los delitos contra la administración pública. Teoría general. Instituto Nacional de Administración Pública, Santiago de Compostela, Universidad de Santiago de Compostela, 2003. 